\title{
INTERDISCIPLINARIDADE EM AÇÃO: A COMUNICAÇÃO COMO AGENTE DE POTENCIALIZAÇÃO DO PERFIL EMPREENDEDOR NAS ÁREAS DE EDUCAÇÃO E GESTÃO
}

\section{Interdisciplinarity in action: communication as an agent to increase the manager profile areas of education and management}

\section{La interdisciplinariedad en la acción: la comunicación como un agente potenciador del perfil emprendedor en la educación y la gestión}

\author{
Roberto Gondo Macedo ${ }^{1}$ \\ Rosana Catarina Rodrigues Lima² \\ Zilá de Souza Lima Gunzburger ${ }^{3}$
}

\begin{abstract}
RESUMO
Os princípios interdisciplinares contemporâneos propiciam ao discente a estrutura organizacional educacional, dinamismo e flexibilidade para o desenvolvimento de práticas de ensino, principalmente no âmbito do ensino superior. O presente artigo objetiva descrever a importância dessa prática presente em diversas áreas do conhecimento, mas com direcionamento para a área de comunicação como um eixo norteador nas interpretações e análise de cenários macro e microssociais. Para exemplificar a aplicabilidade da prática interdisciplinar é utilizada como análise de caso intrínseco, uma IES localizada na região do ABC Paulista, estado de São Paulo, mais precisamente no trânsito da comunicação nos cursos de educação e gestão. Os aspectos de interação, potencialização das práticas de ensino, fatores facilitadores de aplicação e limitadores de implantação são abordados, com o objetivo de fornecer métricas que podem ser analisadas e implantadas em demais IES regidas pelas normatizações brasileiras.
\end{abstract}

Palavras-chave: interdisciplinaridade; comunicação; comunicação mercadológica; imagem corporativa.

\begin{abstract}
The contemporary interdisciplinary principles provide the student educational and organizational structure, dynamism and flexibility for the development of teaching practices, especially in higher education. This article aims at describing the importance of this practice in several knowledge areas, but focusing the communication area as a guiding principle in the interpretation and analysis of macro and micro social scenarios. In order to illustrate the applicability of interdisciplinary practice, an IES (a higher education institution) located in the ABC Paulista, São Paulo state, is used as an intrinsic case analysis, more precisely in the traffic of communication in education and management. The aspects of interaction, enhancement of teaching practices, facilities and limiting the application deployment are discussed, aiming to provide metrics that can be analyzed and implemented in other IES governed by Brazilian standardizations.
\end{abstract}

Keywords: interdisciplinarity; communication; marketing communication; corporate image.

\footnotetext{
${ }^{1}$ Doutorando em Comunicação Social Umesp, Mestre em Administração. Docente dos cursos de especialização da Universidade Metodista de São Paulo e Universidade Presbiteriana Mackenzie / Faculdade de Mauá (Fama). Diretor Editorial da rede nacional POLITICOM. roberto.macedo@mackenzie.br

2 Mestre em Educação Matemática pela PUC - SP. Faculdade de Mauá (Fama). catarinarosana@uol.com.br

${ }^{3}$ Especialista em Gestão Educacional pela Unicamp - SP. Faculdade de Mauá (Fama). zis_lima@uol.com.br
} 


\section{RESUMEN}

Los principios ofrecen la estructura de la interdisciplinaria de estudiantes de la educación contemporánea y organización, dinamismo y flexibilidad para el desarrollo de las prácticas de enseñanza, especialmente en la educación superior. Este artículo tiene por objetivo describir la importancia de esta práctica en diversas áreas del conocimiento, pero con la dirección en el área de la comunicación como un principio rector en la interpretación y análisis de los escenarios macro y micro social. Para ilustrar la aplicabilidad de la práctica de la interdisciplinariedad se utiliza como un análisis intrínseco de casos, un IES (institución de educación superior) ubicado en el ABC Paulista, São Paulo, más precisamente en el tráfico de comunicación en la educación y la gestión. Los aspectos de la interacción, la mejora de las prácticas de enseñanza, instalaciones y limitar el despliegue de la aplicación se analizan, con el objetivo de proporcionar mediciones que pueden ser analizados y aplicados en el IES otros organismos de las estandarizaciones de Brasil.

Palabras clave: interdisciplinariedad; comunicación; comunicación de marketing; imagen corporativa.

\section{Introdução}

A contemporaneidade fomentou comportamentos e ações pautadas em uma alta velocidade de tomada de decisões, convergências de áreas do conhecimento e um viés de integração de meios, criando um cenário acentuadamente global.

O papel da comunicação nesse ambiente ocupa a cada ano um posicionamento mais estratégico e interventor, decorrente da necessidade pulsante dos novos paradigmas do mercado de trabalho, que exigem dos profissionais clara compreensão dos canais midiáticos, mercados e segmentos corporativos, comportamento dos consumidores e telespectadores dos mais diversos perfis diante dos estímulos dirigidos pelas ações da comunicação mercadológica.

Permanecer e conquistar espaços de trabalho nesse mercado integrado e competitivo exige das instituições de ensino, principalmente as de ensino superior, cuja atividade é focada na formação especialista, um posicionamento flexível, dinâmico e agregador dos docentes e discentes de modo a garantir um desenvolvimento de perfil moderno em um ambiente recém-estruturado pós-crise econômica.

O processo de trabalho situa-se no cerne da estrutura social. A transformação tecnológica e administrativa do trabalho e das relações produtivas dentro e em torno da empresa emergente em rede é o principal instrumento por meio do qual o paradigma informacional e o processo de globalização afetam a sociedade em geral (CASTELLS, 1999, p. 265).

No ambiente acadêmico científico nacional $e$ internacional, as pesquisas relacionadas às vertentes da comunicação buscam a cada dia integrar fundamentações e postular pressupostos alinhavados com áreas do conhecimento antes inimagináveis de serem unidas e analisadas.

A compreensão da importância das ações de comunicação empresarial para o segmento corporativo ou até mesmo na concepção de análise de mercado, para o desenvolvimento de ações comunicacionais vinculadas à publicidade, propaganda e marketing, leva os componentes curriculares a promover interações com o panorama do mercado, instigando o aluno à pesquisa observacional e participativa. O desenvolvimento tecnológico contribuiu de maneira incisiva para o estabelecimento de uma integração social baseada em redes de comunicação, condicionando o indivíduo a desenvolver habilidade e competências específicas para acompanhar e controlar a velocidade da informação e geração do conhecimento.

Os pilares da sociedade da informação podem ser alinhavados, segundo visão de Jambeiro (1994, p. 69); como "a informática, 
na sua dimensão de produtoras de softwares; a estrutura de telemática, enquanto rede de telecomunicações computadorizada, interligada nacional e internacionalmente; $e$ a indústria de equipamentos eletro-eletrônicos".

Além do conceito tecnológico que envolve a comunicação como um elo necessário para a compreensão e potencialização do processo, a visão organizacional acerca dos novos paradigmas do administrador de empresa em formação reporta-se à necessidade da interdisciplinaridade da comunicação com a área de gestão organizacional e corporativa.

Segundo Fernandes (2008, p. 175), "é fundamental que o setor empresarial reveja sua forma de produção e comercialização de seus produtos, assim como é importante que a sociedade perceba que consumir não é uma atividade supérflua, mas necessária”.

Esse conceito reporta-se à necessidade de formação de um profissional preparado para compreender a real participação das suas ações no meio ambiente corporativo e social, demonstrando a sua relevância como um agente interventor no processo de melhoria do planeta, iniciando pelas suas atividades de regionalidade.

É indubitavelmente um ambiente desafiador para o aspirante a um cargo no mercado de trabalho, como para o corpo docente universitário, que deve promover, com uma constância acentuada, renovações na forma de integrar conhecimentos, com vista à melhoria da compreensão do corpo discente.

Interdisciplinaridade no cenário contemporâneo educacional

Atualmente, uma das grandes preocupações na área educacional tem sido direcionada à formação do cidadão integral, visto que, por causa das diversas transformações ocorridas em nossa sociedade, exigem-se cada vez mais indivíduos criativos, dinâmicos e, sobretudo, pesquisadores para que possam atender às reais necessidades do mundo globalizado.

Nessa perspectiva, é fundamental o papel do docente em desenvolver um ensino interdisciplinar que permita aos estudantes estabelecer uma inter-relação entre as diferentes áreas do conhecimento, promovendo assim sua capacidade de observar, refletir, transformar, pensar, comunicar e criar.

A implementação de ações interdisciplinares tem sido amplamente discutida por vários autores quando se trata da organização do trabalho escolar e/ou acadêmico e, segundo Machado (1999), existem dois fatores que relacionam-se diretamente com a emergência desse conceito:

\begin{abstract}
Em primeiro lugar, uma fragmentação crescente dos objetos do conhecimento nas diversas áreas, sem a contrapartida do incremento de uma visão de conjunto do saber instituído tem-se revelado crescentemente desorientadora, conduzindo certas especializações a um fechamento no discurso que constitui um óbice na comunicação e na ação. [...] em segundo lugar, parece cada vez mais difícil o enquadramento de fenômenos que ocorrem fora da escola no âmbito de uma única disciplina. Hoje, a Física e a Química esmiúçam a estrutura da matéria, a entropia é um conceito fundamental na Termodinâmica, na Biologia e na Matemática da Comunicação, a Língua e a Matemática entrelaçam-se nos jornais diários, a propaganda evidencia a flexibilidade das fronteiras entre a Psicologia e a Sociologia, para citar apenas alguns exemplos (MACHADO, 1999, p. 180).
\end{abstract}

Distante de um consenso sobre o conceito de interdisciplinaridade, graças a sua complexidade, recorre-se à explicação do termo segundo Fazenda (1995): 
Inter - é um sufixo - dade - que, ao se justaporem ao substantivo disciplina - nos levam à seguinte possibilidade interpretativa, onde: inter, prefixo latino, que significa posição ou ação intermediária, reciprocidade, interação. Por sua vez, dade, sufixo latino guarda a propriedade de substanciar alguns adjetivos, atribuindo-lhes o sentido de ação ou resultado de ação, qualidade, estado ou, ainda, modo de ser. Já a palavra disciplina significa epistermé, podendo ser caracterizada como ordem que convém ao funcionamento de uma organização ou um regime de ordem que convém ao funcionamento duma organização ou um regime de ordem imposta ao livremente consentida (FAZENDA, 1995, p. 23-24).

Nessa perspectiva, a interdisciplinaridade pode ser compreendida como a integração entre disciplinas que busca unificar os saberes. É salutar ressaltar ainda que, para a autora, a interdisciplinaridade transcende a esfera epistemológica, visto que, para o desenvolvimento de um trabalho interdisciplinar, além das atitudes de um professor interdisciplinar, Fazenda (2003) também destaca características que considera fundamentais para uma sala de aula interdisciplinar, pois neste ambiente "[...] todos se percebem e gradativamente se tornam parceiros e, nela, a interdisciplinaridade pode ser aprendida $e$ pode ser ensinada, o que pressupõe um ato de perceber-se interdisciplinar" (p. 86).

Assim, vale pontuar que, a partir de uma proposta interdisciplinar, pautada nos pressupostos elencados, espera-se que o educando sinta prazer em construir seu conhecimento aprendendo a questionar, discutir, refletir, pensar, comunicar, transformar, criar e recriar o mundo que o cerca com maior autonomia.

A sociedade atual exige que a universidade não somente capacite os acadêmicos para futuras habilitações nas especializações tradicionais, mas principalmente, que tenha em vista a formação dos mesmos, para desenvolver suas competências e habilidades em função de novos saberes que se produzem e que exigem um novo tipo de profissional. No Ensino Superior, a falta de contato do conhecimento com a realidade, parece ser uma característica bastante acentuada. Os professores, no esforço de levar seus alunos a aprender, o fazem de maneira a dar importância ao conteúdo em si, e não à sua interligação com a situação da qual emerge, gerando, assim, a clássica dissociação entre teoria e prática (FAVARÃO; ARAÚJO, 2004, p. 103).

O caráter interdisciplinar aplicado ao ensino superior não pode ser considerado predominante, pois sua prática exige da organização de ensino estímulo constante aos docentes para o desenvolvimento e implantação das práticas interdisciplinares, nos conteúdos curriculares dos componentes dos semestres.

Além da orientação do docente de como proceder para conduzir propostas interdisciplinares, é necessária a atribuição de tempo extra para o preparo e formatação do material de uso em atividade, o que, em muitos casos de IES, é considerado um investimento alto, e a proposta de trabalho do componente de maneira isolada é mantida.

A interdisciplinaridade surgiu nos anos 70 como resposta às necessidades de uma abordagem mais integradora da realidade. Ainda que muitas vezes esteja associada a modismo ou à realização de projetos apenas aparentemente ou pseudo-interdisciplinares na área da educação, ela nasce da hipótese de que, por seu intermédio, é possível superar os problemas decorrentes da excessiva especialização, contribuindo para vincular o conhecimento à prática (DENCKER, 2002, p. 19). 
A condução de uma proposta interdisciplinar deve ser aceita pelo corpo diretivo das organizações de ensino superior como um processo constante, cujos resultados surgem a médio e longo prazo, conforme a ambientação e formação do corpo docente com a proposta $e$ sua relevância, bem como a sua aplicabilidade para o corpo discente.

Em um primeiro momento, nem todos os docentes se envolvem com o processo, visto que historicamente o educador de excelência era o que desenvolvia material para uso em sala para o seu componente, independentemente do que estava sendo idealizado e aplicado por outros componentes do semestre ou do ano para os alunos. A visão contemporânea de ensino exige um novo perfil de docente, mais integrador com a necessidade de demais componentes e disposto a propor soluções em conjunto, no que tange à proposta norteadora do curso ou instituição.

Para Luck (2001, p. 61), "com a visão interdisciplinar, o homem deixa de encerrar-se numa única abordagem do conhecimento, para adquirir uma visão global da realidade". Dessa maneira, é mais condizente afirmar que o indivíduo reunirá mais chances de conquistar melhores posições no mercado de trabalho, graças à sua nova postura profissional, comunicacional $e$ gerencial.

Características dos profissionais de educação e administração

As áreas de educação e administração, como base de formação, são citadas nesta pesquisa pelo envolvimento do objeto de estudo, pois a aplicabilidade de ações comunicacionais na IES apresentada no artigo é predominante nos cursos superiores de Licenciatura Plena em Pedagogia e Bacharelado em Administração.
Ambos os cursos têm bases em humanidades e utilizam os conceitos comunicacionais em alguns componentes, com o objetivo de formação de um profissional que possa assumir cargos de liderança e gestão, exercendo suas funções de maneira eficiente e funcional.

A necessidade de uma visão estratégica, ampla e dinâmica é ponto fundamental para o educador contemporâneo, independentemente do nível de ensino atuante. Indiscutivelmente, no mundo globalizado, não há mais espaços para saberes fragmentados que desconsiderem a inter-relação existente entre eles. Nesse sentido, a compreensão do mundo e principalmente desse mundo globalizado, que tanto traz certezas como incertezas, torna-se indispensável para o direcionamento de suas ações.

Nesse cenário, então, o papel do gestor como articulador do projeto político pedagógico não pode deixar de considerar essa totalidade que prevê ao mesmo tempo uma dissecação das partes numa forma quase que dicotômica de entender esse processo.

Há de se considerar, portanto, as peculiaridades de uma sociedade local e escolar, com vistas a uma compreensão de mundo atualizada, evitando posicionamentos infundados e alienados.

Perante essa nova situação, surge então a necessidade de pesquisar e entender novas formas de pensamento sobre a vida política, social, artística e cultural e também dos indivíduos, pressupondo o surgimento de ideias divergentes ou ainda complementares, que são facilmente acessadas pelos meios de comunicação e informação.

Essa situação sumariamente abordada nos leva a uma aproximação crescente com a comunicação e o diálogo entre as pessoas, na difícil tarefa de dizer e fazer-se compreender pelos outros, mas não há outro caminho mais desejável do que o diálogo, para identificar os impasses ao mesmo tempo para uma reflexão salutar e crítica que considere o pessoal e o global, 
confrontando paradigmas e saberes construídos historicamente pelas diferentes culturas existentes no mundo.

Nesse contexto, a comunicação e o diálogo vão se constituindo como formas determinantes da atuação do gestor educacional, considerando também a cultura própria de cada escola e de cada sala de aula e, no que contribui Fazenda (2003), para elucidar esse pensamento:

[...] o homem vai atingindo o conhecimento de si na medida em que se revela. Esse conhecimento de si cresce na medida em que o homem procura conhecer o outro e esse conhecimento do outro só ocorre quando existe uma perfeita identificação entre o eu e o outro, ou seja, o homem só se realiza, só se conhece no "encontro" com o outro (FAZENDA, 2003, p. 55).

Coloca-se, nessa perspectiva, uma categoria a ser muito considerada, que é a questão da identidade, que, segundo Fazenda (2003), está vinculada a uma complicada rede de relações e não pode ser dissociada das vinculações históricas e sociais nas quais os indivíduos se acham inseridos e precisam ser compreendidas em uma proposta interdisciplinar de trabalho, considerando as várias possibilidades que estão imbricadas nos diferentes saberes e, assim, o diálogo e a comunicação entre os indivíduos não podem deixar de considerar essas características individuais.

A questão do diálogo e da comunicação nos remete a outras reflexões, como a da participação dos indivíduos, presentes numa gestão democrática e contemporânea que se pauta no diálogo e na comunicação entre os diferentes segmentos da escola, bem como os problemas advindos dessa participação, que solicita do gestor um olhar multifacetado dos fatos e da realidade.
Nesse sentido, Gutierres e Catani

(2003, p. 74) afirmam

[...] o universo da escola é particularmente complexo e específico; o diálogo só pode ser verdadeiro e frutífero a partir de um esforço de aproximação onde todos tentem perceber e conhecer o outro em seu próprio contexto e a partir de sua própria história constitutiva.

Assim, essa participação feita a partir do diálogo e da comunicação entre os indivíduos poderá explorar diferentes fontes de referência, debates de pensamentos antagônicos e um intercâmbio de ideias numa forma de construir o conhecimento por meio do diálogo, buscando se estabelecer ou se reconhecer a identidade cultural da escola.

Segundo Hernández (1998, p. 56), “a identidade cultural é sempre mais complexa do que sua forma reducionista, porque pressupõe reconhecer as influências entre as culturas $e$ suas inter-relações e as diversas representações presentes na constituição de valores e convicções".

Nessa direção, o gestor deve assumir o desafio de construir seu Projeto Político Pedagógico, com a participação da sociedade, enfrentando os dilemas de estabelecer vínculos entre novos e antigos valores, de trazer à tona as diferentes versões da realidade pela participação dos indivíduos, de forma a não construir práticas fortalecedoras de interesses e valores hegemônicos e, ao contrário, estabelecer debates sobre interpretações conflituosas, identificando e compreendendo suas próprias convicções.

O bacharel em Administração, por sua vez, se depara com um novo cenário de trabalho a partir de 2009 , com a tentativa nacional e internacional de retomada econômica vigente até meados de 2008, antes da crise econômica norte-americana que fomentou um processo em cadeia para países de todo o globo. 
A comunicação para o administrador em função interdisciplinar tem o objetivo de promover uma nova visão com relação ao posicionamento das estratégias comunicacionais nos planos organizacionais da empresa. A compreensão das ações de comunicação apenas como processo operacional é um equivoco no cenário de trabalho atual.

Todas as organizações, independentemente de seus modelos administrativos e de outros atributos que lhe conferem identidade em relação a outras organizações, têm na comunicação um processo complexo, integrante de suas políticas, seus planejamento e suas ações. [...] é por meio da comunicação que ela esta estabelece diálogos a respeito de suas políticas, suas ações e suas pretensões, informa, organiza e reconhece os seus públicos de interesse, entre os quais seus colaboradores, legitima a sua existência e trabalha para a melhoria do ambiente de trabalho, entre outros objetivos (NASSAR, 2008, p. 64).

O perfil empreendedor é um dos eixos norteadores do novo modelo de gestor $e$ tomador de decisões empresariais, sempre com base em análises de cenários e compreendendo a importância da comunicação organizacional, mercadológica, visando à construção sustentável de uma empresa, independentemente do segmento de atuação.

$\mathrm{O}$ aspecto convergente também se estende para o nível de pós-graduação lato sensu e stricto sensu, pois muitos cursos na área de gestão recebem interessados da área comunicacional, como também é verdade a recíproca quando se têm administradores nos cursos relacionados a marketing, comunicação empresarial, jornalismo e mídias.

Na concepção de Yanaze e Markus (2008, p. 222), "o dinamismo do mercado obriga as organizações a acelerar cada vez mais o processo de planejamento e a adotar uma postura de administração estratégica para responder imediatamente as demandas e aos desafios mercadológicos".

Gerenciar organizações na atualidade exige um perfil interpretativo das dinâmicas de mercado, em uma velocidade nunca antes vista. O prisma comunicacional propicia ao administrador uma sensibilidade maior no que tange à previsão de potenciais retornos de mercado.

\section{Uma aplicação interdisciplinar: a facul- dade de Mauá (Fama)}

A Faculdade de Mauá é uma IES com oito anos de existência, com campus na cidade de Mauá, na região do ABC Paulista, estado de São Paulo. Conta com um portfólio de 10 cursos de ensino superior que são direcionados ao perfil da demanda existente na região, caracterizada pela acentuada produção industrial e crescente mercado na área se serviços, sendo eles Administração, Pedagogia, Serviço Social, Ciências Contábeis e Sistemas de Informação (Bacharelado e Licenciatura), dois tecnológicos em Processos de Produção e Gestão Financeira, como também Enfermagem, Nutrição e Educação Física, na área da saúde.

Cursos de pós-graduação lato sensu também são oferecidos com o mesmo conceito de ensino interdisciplinar, criando um ambiente de laboratório nas ações de planejamento $e$ análise de cenários.

No somatório dos cursos, a IES apresenta aproximadamente 1400 alunos regularmente matriculados e, desde o seu primeiro ano de atuação, estruturou-se na proposta pedagógica socioconstrutivista interacionista, fomentadora do conceito interdisciplinar, disseminada na instituição pela prof ${ }^{a}$. Dr ${ }^{a}$. Ilca Oliveira de A. Vianna.

Apesar de não ter cursos na área de comunicação, sua abordagem interdisciplinar 
permite que os pressupostos comunicacionais transitem com facilidade pelo cotidiano de atividades interacionistas, principalmente nos cursos de Administração e Pedagogia, citados nesta pesquisa.

Para atingir os resultados de interação, todos os docentes participam de reuniões pedagógicas periódicas com a finalidade de alinhavar procedimentos metodológicos e, consequentemente, fortalecem a base das ementas para o recebimento de ações integradas. $\mathrm{O}$ acompanhamento com retorno dos alunos é discutido periodicamente, criando um debate acerca das estratégias que podem ser aplicadas para a melhoria do processo.

Torna-se evidente que o número aproximado de 90 docentes contribui para que o processo obtenha resultados satisfatórios, visto que é factual a dificuldade de alinhavar projetos e propostas para um contingente alto de docentes em diversas IES nos estados da federação.

O curso de Licenciatura em Pedagogia desenvolve, durante o processo de formação, projetos relacionados ao empreendedorismo $e$ marketing educacional, interagindo com a comunicação mercadológica para a construção de planejamentos de mercado, análise de cenários, abordagens de público certo para a oferta de seus serviços educacionais, bem como a construção de uma imagem sustentável para a regionalidade, integrando conceitos relacionados ao meio ambiente e inclusão digital, dentre outros.

Os conteúdos de comunicação também são apresentados aos alunos na importância de construção de um perfil educador ambientado com as necessidades da sociedade, principalmente no tratamento dos diversos veículos de comunicação e canais midiáticos, que, quando bem integrados, podem contribuir incisivamente para o desempenho das atividades no segmento educacional.

O maior projeto do curso relacionado aos conceitos interdisciplinares comunicacionais envolve a idealização de uma escola privada, que transite desde o desenvolvimento do Plano Diretor em educação até a campanha publicitária da escola, visando a atrair potenciais clientes, com identidade visual, planejamento de interação com a mídia, ações de marketing de eventos, digital e social, como também o foco no empreendedor comunicador.

O curso de Bacharelado em Administração também reporta ações acadêmicas que interagem com o universo comunicacional, por intermédio de projetos de criação de empresas, com planejamento mercadológico, incluindo pesquisa de mercado e análise de concorrência para o lançamento de produtos nos mais diversos segmentos existentes no mercado. As "empresas" montadas pelos alunos interagem com a sociedade local, promovendo um lançamento do produto, com todas as aplicações mercadológicas e publicitárias.

Apresentam também como irão proceder nas ações de comunicação organizacional e empresarial, principalmente no tratamento com a rede de fornecedores, colaboradores $e$ clientes, com planejamento de fidelização de mercado consumidor e ações de crescimento sustentável.

Com relação ao processo de responsabilidade social corporativa, todos os grupos formados, já com a identidade institucional da empresa criada de modo fictício, promovem a prática de ações de sustentabilidade como necessárias para o desenvolvimento sustentável da organização, estruturada em novos conceitos de mercado e do novo comportamento do consumidor.

Cada "empresa" desenvolve suas ações direcionadas ao seu segmento de atuação no mercado, vinculando o seu produto com características de diferencial de produção ou de uso perante os produtos simulares existentes no mercado.

A comunicação organizacional e empresarial conduz o discente a manifestar a importância dessas ações na construção de um 
ambiente mais agradável de viver com a integração da responsabilidade de contribuir para a melhoria da qualidade de vida da sociedade.

O antídoto para a sustentabilidade e para o consumo consciente deve passar, necessariamente, por uma mudança cultural nos hábitos de cada sociedade. A sustentabilidade deve ser do interesse dos empresários, pois a perpetuação das organizações depende da preservação do meio ambiente e da valorização social (FERNANDES, 2008, p. 176).

Essas práticas interdisciplinares permitem ao corpo discente compreender a real necessidade da busca pela interação, criando mecanismos de sucesso no seu posicionamento no mercado de trabalho da atualidade, tendo condições plenas de assumir cargos de liderança e planejamento no novo conceito organizacional.

\section{Considerações finais}

Diante de uma realidade competitiva e com alto grau de velocidade na inovação dos conceitos, é pertinente ressaltar a importância do processo interdisciplinar para o fortalecimento da formação do discente, principalmente na formação no nível superior, no qual o direcionamento educacional é mais evidente.

Aplicar o processo interdisciplinar é desafiador para todas as IES, principalmente para as organizações mais tradicionais que já se estruturaram em parâmetros de décadas passadas e necessitam romper paradigmas formados culturalmente durante anos.

Para as instituições mais recentes e com uma estrutura organizacional menor e mais enxuta, a aplicação também pode ser considerada complexa, mas com maior grau de aceitabilidade perante o corpo docente, que é ponto integrador e fundamental para a eficácia da proposta $e$ eficiência da aplicabilidade.

A interdisciplinaridade pode contribuir incisivamente na superação da dissociação do conhecimento produzido e sua aplicabilidade estimula a orientação para a produção de uma nova estrutura de conhecimento, constituindo ambiente necessário para a melhoria da qualidade do ensino superior, combatendo o processo individualizado $e$ fomentando a orientação para a formação do profissional realmente global.

Nas aplicações interdisciplinares nos cursos de Pedagogia e Administração, é evidente o alto grau de aproveitamento discente diante dos desafios impostos em caráter de integração nos projetos. As aplicações formam um conjunto que propicia uma visão macro das ações necessárias para o sucesso de um projeto.

Em ambos os cursos, a preocupação com as vertentes em comunicação é igualmente respeitada com relação aos demais processos, como o financeiro e matemático, principalmente quanto à formação de preços e análise de mercado, seja para a educação ou qualquer outro segmento.

Nesse contexto, é pertinente reportar a grande responsabilidade das organizações de ensino em compreender que a implantação de uma cultura interdisciplinar não é para ser considerada com um "gasto" a ser cortado ou limitado, mas sim como investimento na formação dos docentes e, consequentemente, dos discentes, que terão mais chances de sucesso no mercado de trabalho atual. 


\section{REFERÊNCIAS}

CASTELLS, Manuel. A sociedade em rede. São Paulo: Paz e Terra, 1999.

DENCKER, Ada Freitas Maneti. Pesquisa e interdisciplinaridade no ensino superior: uma experiência no curso de turismo. São Paulo: Aleph, 2002.

FAVARÃO, Neide Rodrigues Lago; ARAÚJO, Cíntia Souza Alferes. Importância da interdisciplinaridade no ensino superior. Educere, Umuarama, v. 4, n. 2, p. 103-115, jul./dez. 2004.

FAZENDA, Ivani Arantes. Interdisciplinaridade: história, teoria e pesquisa. 4. ed. Campinas: Papirus, 2003. $\overline{\text { Cortez, }} 1995$.

Práticas interdisciplinares na escola. São Paulo:

FERNANDES, Backer Ribeiro. A comunicação e o consumo consciente. In: MELO, José Marques de. Mídia, ecologia e sociedade. São Paulo: Intercom, 2008.

GUTIRREZ, Gustavo Kuis; CATANI, Afrânio Mendes. Participação e gestão escolar: conceitos e potencialidades, In: FERREIRA, Naura Syria Carapeto. (Org.) Gestão democrática da educação: atuais tendências, novos desafios. 4. ed. São Paulo: Cortez, 2003.

HERNÁNDEZ, Fernando. Transgressão e mudança na educação: os projetos de trabalho. Tradução Jussara Haubert Rodrigues. Porto Alegre: Artmed, 1998.

JAMBEIRO, Othon. Brasil na sociedade da informação: bases de um esquema de análise. In: JAMBEIRO, Othon;
BOLAÑO, César; BRITTOS, Valério (Orgs.). Comunicação, informação e cultura: dinâmicas globais e estruturas de poder. Salvador: UFBA, 2004.

LUCK, Heloisa. Pedagogia interdisciplinar: fundamentos teórico-metodológicos. 9. ed. Petrópolis: Vozes, 2001.

MACHADO, Nilson José. Epistemologia e didática: as concepções de conhecimento e inteligência e a prática docente. 3. ed. São Paulo: Cortez, 1999.

NASSAR, Paulo. Conceitos e processos de comunicação organizacional. In: KUNSCH. Gestão estratégica em comunicação organizacional e relações públicas. São Caetano do Sul: Difusão, 2008.

SANTOMÉ, Jurjo Torres. Globalização e interdisciplinaridade: o currículo integrado. Porto Alegre: Artmed, 1998.

YANAZE, Mitsuru Higuchi; MARKUS, Kleber. O Marketing como gestão organizacional. In: KUNSCH. Gestão estratégica em comunicação organizacional e relações públicas. São Caetano do Sul: Difusão, 2008.

Texto recebido em 20 de março de 2009. Texto aprovado em 20 de agosto de 2009. 